(2) Open Access Full Text Article

REVIEW

\title{
An insight into light as a chronobiological therapy in affective disorders
}

\author{
This article was published in the following Dove Press journal: \\ ChronoPhysiology and Therapy \\ 4 October 2014 \\ Number of times this article has been viewed
}

\section{Jacqueline MWalsh \\ Lynsey A Atkinson \\ Sarah A Corlett \\ Gurprit S Lall}

Medway School of Pharmacy, University of Kent, Chatham, Kent, UK
Correspondence: Gurprit S Lall Medway School of Pharmacy, University of Kent, Central Avenue, Chatham, Kent, ME4 4TB, UK

Tel +44 I634 202946

Fax +44I634883927

Email g.lall@kent.ac.uk
Abstract: The field of chronobiology has vastly expanded over the past few decades, bringing together research from the fields of circadian rhythms and sleep. The importance of the environmental day-night cycle on our health is becoming increasingly evident as we evolve into a 24-hour society. Reducing or changing sleep times against our natural instincts to rest at night has a detrimental impact on our well-being. The mammalian circadian clock, termed "the suprachiasmatic nucleus", is responsible for synchronizing our behavioral and physiological outputs to the environment. It utilizes light transcoded by specialized retinal photoreceptors as its cue to set internal rhythms to be in phase with the light-dark cycle. Misalignment of these outputs results in symptoms such as altered/disturbed sleep patterns, changes in mood, and physical and mental exhaustion - symptoms shared by many affective clinical disorders. Key links to circadian abnormalities have been found in a number of disorders, such as seasonal affective disorder, nonseasonal depression, and bipolar affective disorder. Furthermore, therapies developed through chronobiological research have been shown to be beneficial in the treatment of these conditions. In this article, we discuss the impact of circadian research on the management of affective disorders, giving evidence of how a misaligned circadian system may be a contributor to the symptoms of depression and how moderating circadian rhythms with light therapy benefits patients.

Keywords: circadian, depression, SAD, nonseasonal, bipolar

\section{Introduction}

Chronobiology is a vastly expanding field of research, incorporating both areas of circadian rhythms and sleep. Over the last decade, these two disciplines have become increasingly integrated, resulting in a better understanding of mechanisms that underpin both our physiological and behavioral daily routines. Consequently, these emerging principles are now being translated into the clinical setting and are proving to be fundamental, as the importance of both circadian rhythms and sleep in the preservation of human health is unraveled.

Through evolution, the environmental day-night cycle has been the predominant cue to which organisms have adapted their behavior. Humans have evolved into a diurnal species, preferring to sleep at night and restrict activity to the day. This daily pattern in synchronization has held true for centuries; however, modern society has begun to break away from this norm. With the advent of a "24-hour society", we find ourselves paying less attention to our natural instincts to rest and rather favor socializing and working. Remarkably, many individuals turn to stimulants to prolong daily "active" duration in the pursuit of maximizing "awake" efficiency. However, continually 
reducing the duration of rest or sleep is likely to be a key contributor to the "burnout" phenomenon, manifesting as extreme tiredness, mental exhaustion, and low mood. Thus, this cultural drift in day-night activity impacts negatively on our overall psychological well-being and health.

The synchronization of our daily behavior to the environmental day-night cycle is governed by an inherent biological clock. This clock integrates light cues and our social signals to generate a harmonic balance between internal physiology and the outside world. However, a misalignment in such a system, due to either a self-driven motivation or a clinical disorder, can result in ill health. ${ }^{1}$ Recently, it has been shown that some of the characteristic symptoms of natural aging, for instance, abnormal sleep patterns, are likely to be a result of a circadian desynchronization. ${ }^{2}$ Complex neurological conditions such as affective disorders also share common symptoms that are suggestive of a deficit in circadian regulation. Treatments that are aimed at realigning or stabilizing physiological synchronicity with the environment have proven beneficial in seasonal affective disorder (SAD), nonseasonal depression, and bipolar affective disorders. ${ }^{3}$ In this article, we discuss and highlight the importance of chronobiology in affective disorders. In addition, we aim to show the impact of therapies devised from our current understanding of circadian biology to treat these conditions and their beneficial effect on patients.

\section{The master clock and circadian entrainment}

Mammals possess a master neuronal circadian pacemaker, the suprachiasmatic nucleus ( $\mathrm{SCN}$ ), which is situated within the anterior hypothalamus, beneath the third ventricle and above the optic chiasm. ${ }^{4}$ The SCN receives direct photic input from the eyes via the retinohypothalamic tract, providing vital information about the environmental day-night cycle. In addition, the $\mathrm{SCN}$ is also innervated by projections from the intergeniculate leaflet and raphe nucleus, which relay non-photic information, such as social and behavioral cues, to the clock.

Neurons of the SCN are endogenously rhythmic. ${ }^{5}$ These cells express circadian oscillations in both molecular gene expression of specific clock genes and in cellular electrical excitation. ${ }^{5,6}$ It is these rhythms that align themselves in response to photic and non-photic information received from afferent inputs. For instance, under a typical day-night cycle, the SCN displays increased electrical excitation during the day relative to the night. ${ }^{7}$ It is these outputs that will, in turn, provide a timing cue for other physiological systems, such as those governing sleep.
For humans, this synchronization presents itself through our preference to be active during the day and asleep at night. In addition, such synchronization can be modified by other neuronal systems governed by behavioral stimuli, such as social activities, meal times, and exercise. The incorporation of these behavioral signals and the light-dark cycle provides ultimate entrainment of an individual. For the purpose of this review, we will focus on aspects of circadian entrainment that have been identified to contribute to the mood disorders discussed in subsequent sections. For a detailed review on entrainment mechanisms, see Lall et al. ${ }^{8}$

\section{Light input to the circadian clock}

In mammals, light information enters the physiological system exclusively via the eye. ${ }^{9}$ This ocular detection of ambient light intensity, or irradiance, performs a significant role in circadian entrainment in addition to image-forming vision. ${ }^{10}$ When light reaches the retina, three classes of photoreceptor cells - rods, cones, and intrinsically photoreceptive retinal ganglion cells (ipRGCs) - decode and communicate photic information for further processing. For the purpose of visualization, rod and cone photoreceptors provide the core translational pathway; however, the task of circadian photoentrainment has been largely attributed to the subset of retinal ganglion cells possessing the novel photopigment melanopsin: the ipRGCs. For a detailed review on photoreceptor contribution to circadian entrainment, see Lucas et al. ${ }^{11}$

Light-evoked innervations from the combined actions of all classes of photoreceptor are signaled directly to the SCN via multisynaptic circuitry of the retinohypothalamic tract. These act to drive non-image-forming (NIF) responses of circadian photoentrainment, pupillary light reflex, pineal melatonin suppression, and sleep propensity. ${ }^{12-14}$ However, the communicated photic information is not defined simply by duration of light, as retinal sensitivity is subject to irradiance and spectral composition. ${ }^{11,15}$ It has been shown experimentally that the rod class of photoreceptor has the greatest sensitivity to light, with very low illumination still able to contribute to photoentrainment in the absence of other NIF responses. ${ }^{13,16,17}$ Under higher levels of irradiance, cones play a greater role in retinal decoding and, in turn, NIF responses, but essentially the melanopsin-containing ipRGCs provide the greatest contribution. ${ }^{13}$ Further, photoreceptor sensitivity has been demonstrated to vary according to wavelength of light. ${ }^{15}$ For melanopsin, peak sensitivity occurs around $480 \mathrm{~nm}$, suggesting lighting within the blue spectral range as being optimal for eliciting entraining photic cues. ${ }^{18-20}$ Despite this class of photoreceptor being maximally sensitive 
to light and able to integrate ambient light levels throughout the duration of an entire day, it possesses very low sensitivity, requiring bright light for optimal signaling. Together, this has formed the basis of light therapy treatments typically comprising bright white or blue lights which are given during the day with the sole purpose of activating the melanopsin system and increasing photic signaling to the circadian clock, thus increasing the daylight signal to, in turn, drive circadian synchronization (entrainment).

\section{Light as a therapeutic tool}

A desynchronized circadian system results in significant changes in mood and sleep, such as those acutely experienced during jetlag. However, it is the presence of light that is able to drive the resynchronization of these systems through the SCN. Hence, this knowledge and understanding of the circadian system has led to the use of light in the treatment of psychiatric conditions that show symptoms of a destabilized clock. Bright bursts of light can act as strong signals to the $\mathrm{SCN}$, thereby reinforcing daylight presence. Early controlled studies using bright light as a therapeutic tool for 3 hours in the morning and 3 hours in the evening during the winter months proved an effective treatment for SAD "winter depression", with the light stimulus acting to elongate the amount of daylight available throughout the day. ${ }^{21}$

Initially, light treatments for longer durations at lower intensities (approximately 2,500 lux) were shown to be effective in eliciting an antidepressant response. ${ }^{21}$ However, increasing light intensity to 10,000 lux for 30-40 minutes yielded comparable remission rates in subsequent SAD studies. ${ }^{22,23}$ In addition to intensity, spectral composition of light may be important. Typically polychromatic "white light" has shown greatest efficacy. ${ }^{21}$ However, following the discovery of melanopsin, light stimuli shifted toward the blue visual spectral range may be beneficial in achieving greater potency. ${ }^{24}$

In addition to discrete bursts of light, a paradigm simulating the onset of dawn using illumination has also shown promise in the treatment of affective disorders. Such dawn simulation treatments are administered at the end of the night, lasting up to 2 hours in duration, during which environmental lighting is raised gradually from darkness to $250 \mathrm{lux}$, thus mimicking sunrise. ${ }^{25,26}$ Difficulty in awakening is often a common symptom found in SAD patients, and it is likely that dawn simulation acts to alleviate such symptoms by decreasing morning drowsiness. ${ }^{27-29}$ In addition, such treatment has been shown to generate greater remission and response rates when compared against therapies involving a single pulse of bright light. ${ }^{30}$ Finally, it has been proposed that dawn simulation induces its effect by altering circadian phase in individuals. ${ }^{31}$

Adverse effects associated with light treatment are minimal. Several studies describe mild visual disturbances, including eyestrain and photophobia. ${ }^{21}$ Agitation, headaches, and eye irritations are reported across affective disorder trials; ${ }^{21}$ however, these are likely to be significantly minimized in dawn simulation paradigms. In a review of nonseasonal light therapy trials, the frequency of these symptoms was not shown to be significantly different from the control groups. ${ }^{32}$ In terms of ocular safety, a study of long-term exposure to light treatment did not reveal ophthalmological problems in participants. ${ }^{33,34}$ Overall, light therapy is considered well tolerated and safe, and presents with a convincing risk-to-benefit ratio. ${ }^{33}$

\section{Chronotherapeutics and affective disorders}

Over the last few decades, research into both mammalian circadian rhythms and sleep has been rapidly progressing, with a growing wealth of knowledge in the basic understanding of mechanisms that underlie each process. More recently, the realization of the importance of these findings in human health has been brought to the forefront. For example, the association between changes in various circadian rhythms and the occurrence of mood disorders has been extensively documented. Specifically, abnormalities in patterns in biochemical, neuroendocrine, physiological, and behavioral outputs have been widely observed in patients suffering from affective disorders. ${ }^{35}$ In this section, we will focus on the chronobiological significance and impact of light on seasonal, nonseasonal, and bipolar affective disorders.

\section{Seasonal affective disorder}

SAD is a clinical subtype of major depression, first defined in a seminal report by Rosenthal et al in $1984 .{ }^{28} \mathrm{SAD}$, or winter depression, presents in patients during the autumn and winter months with symptoms such as severe changes in mood, energy, and appetite. ${ }^{36}$ The seasonal dependence of SAD is strongly correlated with the decrease in daylight hours during symptomatic months. Conversely, as the day length increases, these symptoms are attenuated, leading to remission in the summer. The underlying mechanisms driving SAD have been associated with a deficit of the circadian system to adapt to the changing environment, predominately the lightdark cycle. The precise workings remain unclear; however, a number of key candidates or pathways have been proposed, 
centering on the desynchronization of internal circadiandriven physiology with the external environment.

In the first instance, changes in hormonal rhythms have been linked to SAD onset; of particular interest is the hormone melatonin, referred to as the "sleep hormone". Melatonin levels typically rise at night and reach their lowest point during the day. The majority of circulating melatonin is produced by the pineal gland. The rhythmic profiling of melatonin is regulated, in part, by the light-dark cycle, as light acts to suppress production, thus driving the cyclic nature of this hormone. ${ }^{37}$ More significantly, the onset in expression of melatonin provides a strong biomarker for assessing circadian synchronization..$^{38}$ Dim light melatonin onset (DLMO) is a useful indicator obtained by collection of sequential blood or saliva samples every 30-60 minutes, from early evening until bedtime, under dim light conditions. This marker provides an excellent output of internal physiological entrainment when correlated to the environmental light-dark and sleep cycles. ${ }^{39}$

Sufferers of SAD exhibit a number of traits linked to this defined melatonin rhythm. Affected patients have been shown to express a delay in the DLMO coupled with a lengthened nocturnal and elevated secretion profile during the winter. ${ }^{40-43}$ Due to the responsiveness of melatonin secretion to light, one of the major treatment strategies for SAD has centered on using light as a therapeutic agent. Bright light presented to patients during the morning or during both the morning and afternoon for around 3 hours resulted in significant remission rates in SAD individuals. ${ }^{21,28}$ The positive impact of light in the treatment of SAD is clear; however, its mode of action through adjustment of DLMO is still debatable, thus the antidepressant efficacy of light therapy cannot be defined by its effect on melatonin secretions alone. ${ }^{40,44,45}$ To this end, it has been proposed that light acts by resetting key internal rhythms governed by the circadian clock, thus realigning physiological phase to the environment. ${ }^{41,46}$

In addition to melatonin, the neurotransmitter serotonin (5-hydroxytryptamine [5-HT]) has been associated with modulation of behavior, emotion, and circadian rhythms. ${ }^{47}$ Interestingly, hypothalamic serotonin concentrations investigated in postmortem samples revealed a distinctive seasonal pattern, with lower levels of serotonin detectable in the winter. ${ }^{48}$ In addition, there is a higher degradation of serotonin associated with light environments characteristic of winter months, and an amplified rate of serotonin production in direct response to bright sunlight. ${ }^{49}$ Further, reduced brain serotonin levels share many similarities to SAD, for instance, carbohydrate craving, hyperphagia, hypersomnia, and attenuated melatonin levels. ${ }^{36}$ The role of serotonin in $\mathrm{SAD}$ is, however, uncertain. Acute reduction in serotonin levels in SAD patients remitting during the summer months has been shown to force sufferers into depressive relapse. ${ }^{50-52}$ However, there is variability in the data, with other groups showing little or no effect. ${ }^{53,54}$ Depressive severities in SAD patients are also unaffected by indirect depletion of serotonin levels. ${ }^{55,56}$ Together, these findings call into question the role and specificity of a disrupted serotonergic drive. Interestingly, SAD patients treated with pharmacological agents that increase serotonin together with light treatments did not respond significantly more than those using light alone; however, relapse rates in those taking the combination were slower. ${ }^{57}$

\section{Nonseasonal depression}

The association between nonseasonal depression and chronobiology is one that is not made very often by clinicians or patients; however, there is accumulating evidence that has strengthened the link between circadian disruptions and the characteristic symptoms of nonseasonal depression. These include delayed sleep onset, non-restful sleep, early morning waking, daytime fatigue, and diurnal mood variation. ${ }^{35}$ Typical treatments have focused predominantly on pharmacological interventions, mainly targeting the serotonergic pathways. The most commonly used are selective serotonin reuptake inhibitors (SSRIs), which act to increase endogenous levels of serotonin.

Having established commonalities among symptoms with SAD, the effectiveness of light treatment in nonseasonal depression has been investigated. Interestingly, therapeutic use of light in nonseasonal depressive individuals has shown optimal results at high intensities ( $>2,500$ lux) scheduled to last between 30 minutes and 2 hours - a similar effect size to that observed in SAD patients. ${ }^{32,58}$ Further, the combination of light regimens with antidepressant compounds such as imipramine, sertraline, and citalopram has been shown to significantly improve mood, with faster response rates than an antidepressant-only control group. ${ }^{59-63}$ In addition, melatonin levels have also been found to show significant differences in patients with nonseasonal major depression when compared with healthy individuals. ${ }^{64}$ Due to the very nature of nonseasonal depression and its multifactorial causes and symptoms, a purely chronobiological light-driven treatment regime would be difficult to apply. However, it is likely that some patients may benefit from those interventions that target specific circadian-related symptoms - if nothing else, to alleviate those patients specifically from their suffering. 


\section{Bipolar affective disorder}

Bipolar affective disorder presents with a complex etiology and patients alternate between unpredictable mood states, typically between depression and normal affect or between depression and manic state ${ }^{65}$ In general, behavioral therapies are used with caution in this population due to the unstable and temperamental nature of the disorder. However, patients have been found to respond to light treatments in a similar manner observed in a nonseasonal depressive group. ${ }^{47,65}$ Chronotherapeutic strategies have included sleep deprivation in combination with light treatments to good effect, with rapid antidepressant responses observed, within 48 hours in some cases, which were sustained for a noteworthy 7 weeks. ${ }^{66,67}$ However, light therapy in this population can result in a switch to mania or hypomania in response to treatment. ${ }^{58}$ Thus, it is imperative that the use of light therapy is closely monitored to avoid such relapses. Currently, pharmacological interventions show the greatest promise in the treatment of bipolar affective disorder, but therapies centered on strengthening circadian physiological and behavioral output are showing promise.

\section{Pharmacological chronobiotic interventions}

A range of pharmacological agents have been utilized in the management of affective disorders, employing direct or indirect chronobiotic properties. Lithium, a mainstay psychopharmacological treatment in bipolar disorder, is known to consistently alter circadian phase of an individual. ${ }^{68}$ Melatonin formulations, such as Circadin ${ }^{\circledR}$, and melatonin analogs, including ramelteon and tasimelteon, are found to be effective treatments in a range of insomnia disorders, but have not been studied extensively as antidepressant agents. ${ }^{69-71}$

Selective serotonin reuptake inhibitors (SSRIs) are widely used as first-line treatments in clinical practice for the treatment of SAD and nonseasonal depression. ${ }^{72}$ The precise mechanism of action is debatable, but SSRIs influence the serotonergic system to improve overall mood. ${ }^{73}$ Interestingly, SSRIs have been found to alter circadian rhythms at both cellular and behavioral levels; ${ }^{74,75}$ hence, it is likely that some of the positive effects of SSRIs are through their regulation of the circadian system.

However, SSRI use is commonly associated with serious adverse effects, including reported gastrointestinal effects, weight changes, sexual dysfunction, and sleep disturbances. Indeed, recent media attention has highlighted previously unrecognized side effects of SSRI use during pregnancy causing birth defects during development in utero. ${ }^{76}$ Moreover, SSRIs have a slow onset of action, thus it can be 2-8 weeks or more before a detectable therapeutic response is achieved. Consequently, it is not surprising that the adherence of patients to SSRIs is poor, with a recent study reporting $40 \%-50 \%$ failure during the maintenance period of treatment. ${ }^{77}$

Recently, a novel dual melatonergic and specific serotonergic antidepressant, agomelatine (Valdoxan), has shown potential in SAD patients. ${ }^{78}$ This compound aims to address both the abnormalities in the DLMO and the decrease in serotonin levels found in SAD. Agomelatine has been observed to demonstrate a rapid onset of action and effective symptomatic alleviation and offers a lower risk of relapse or discontinuation of symptoms in nonseasonal depressive individuals when compared to either a comparator or placebo.

\section{Conclusion}

Research into circadian rhythms and sleep has opened up a whole new avenue in our understanding of many clinical conditions. Of these, affective disorders appear to have aspects of circadian dysfunction that are clearly presented in their symptoms. However, the treatment regimes are not so clear-cut. Pharmacological interventions show potency, but can be hindered by undesirable side effects. Conversely, the use of light as a therapeutic aid shows great promise; coupled with potentially minimal or no unwanted side effects. It is imperative that we continue to work on optimizing such chronobiological interventions so as to fully realize their analeptic potential.

\section{Disclosure}

The authors report no conflicts of interest in this work or in any pharmacological interventions discussed.

\section{References}

1. Baron KG, Reid KJ. Circadian misalignment and health. Int Rev Psychiatry. 2014;26(2):139-154.

2. Farajnia S, Deboer T, Rohling JH, Meijer JH, Michel S. Aging of the suprachiasmatic clock. Neuroscientist. 2014;20(1):44-55.

3. Asarnow LD, Soehner AM, Harvey AG. Basic sleep and circadian science as building blocks for behavioral interventions: a translational approach for mood disorders. Behav Neurosci. 2014;128(3):360-370.

4. Ralph MR, Lehman MN. Transplantation: a new tool in the analysis of the mammalian hypothalamic circadian pacemaker. Trends Neurosci. 1991;14(8):362-366.

5. Brown TM, Piggins HD. Electrophysiology of the suprachiasmatic circadian clock. Prog Neurobiol. 2007;82(5):229-255.

6. Reppert SM, Weaver DR. Molecular analysis of mammalian circadian rhythms. Annu Rev Physiol. 2001;63:647-676.

7. Shibata S, Oomura Y, Kita H, Hattori K. Circadian rhythmic changes of neuronal activity in the suprachiasmatic nucleus of the rat hypothalamic slice. Brain Res. 1982;247(1):154-158. 
8. Lall GS, Atkinson LA, Corlett SA, Broadbridge PJ, Bonsall DR. Circadian entrainment and its role in depression: a mechanistic review. J Neural Transm. 2012;119(10):1085-1096.

9. Foster RG. Shedding light on the biological clock. Neuron. 1998;20(5):829-832.

10. Lucas RJ, Foster RG. Neither functional rod photoreceptors nor rod or cone outer segments are required for the photic inhibition of pineal melatonin. Endocrinology. 1999;140(4):1520-1524.

11. Lucas RJ, Lall GS, Allen AE, Brown TM. How rod, cone, and melanopsin photoreceptors come together to enlighten the mammalian circadian clock. Prog Brain Res. 2012;199:1-18.

12. Güler AD, Ecker JL, Lall GS, et al. Melanopsin cells are the principal conduits for rod-cone input to non-image-forming vision. Nature. 2008;453(7191):102-105.

13. Lall GS, Revell VL, Momiji H, et al. Distinct contributions of rod, cone, and melanopsin photoreceptors to encoding irradiance. Neuron. 2010;66(3):417-428.

14. Peirson SN, Halford S, Foster RG. The evolution of irradiance detection: melanopsin and the non-visual opsins. Philos Trans R Soc Lond B Biol Sci. 2009;364(1531):2849-2865.

15. Enezi J, Revell V, Brown T, Wynne J, Schlangen L, Lucas R. A "melanopic" spectral efficiency function predicts the sensitivity of melanopsin photoreceptors to polychromatic lights. J Biol Rhythms. 2011;26(4):314-323.

16. Altimus CM, Güler AD, Alam NM, et al. Rod photoreceptors drive circadian photoentrainment across a wide range of light intensities. Nat Neurosci. 2010;13(9):1107-1112.

17. Butler MP, Silver R. Divergent photic thresholds in the non-imageforming visual system: entrainment, masking and pupillary light reflex. Proc Biol Sci. 2011;278(1706):745-750.

18. Hattar S, Lucas RJ, Mrosovsky N, et al. Melanopsin and rod-cone photoreceptive systems account for all major accessory visual functions in mice. Nature. 2003;424(6944):76-81.

19. Lucas RJ, Douglas RH, Foster RG. Characterization of an ocular photopigment capable of driving pupillary constriction in mice. Nat Neurosci. 2001;4(6):621-626.

20. Rollag MD, Berson DM, Provencio I. Melanopsin, ganglion-cell photoreceptors, and mammalian photoentrainment. J Biol Rhythms. 2003;18(3):227-234.

21. Terman M, Terman JS. Light therapy for seasonal and nonseasonal depression: efficacy, protocol, safety, and side effects. CNS Spectr. 2005;10(8):647-663; quiz 672.

22. Magnusson A, Kristbjarnarson H. Treatment of seasonal affective disorder with high-intensity light. A phototherapy study with an Icelandic group of patients. J Affect Disord. 1991;21(2):141-147.

23. Terman JS, Terman M, Schlager D, et al. Efficacy of brief, intense light exposure for treatment of winter depression. Psychopharmacol Bull. 1990;26(1):3-11.

24. Meesters Y, Dekker V, Schlangen LJ, Bos EH, Ruiter MJ. Low-intensity blue-enriched white light (750 lux) and standard bright light (10,000 lux) are equally effective in treating SAD. A randomized controlled study. BMC Psychiatry. 2011;11:17.

25. Avery DH, Bolte MA, Dager SR, et al. Dawn simulation treatment of winter depression: a controlled study. Am J Psychiatry. 1993;150(1): 113-117.

26. Terman M, Terman JS. Controlled trial of naturalistic dawn simulation and negative air ionization for seasonal affective disorder. $\mathrm{Am} \mathrm{J}$ Psychiatry. 2006;163(12):2126-2133.

27. Avery DH, Kouri ME, Monaghan K, Bolte MA, Hellekson C, Eder D. Is dawn simulation effective in ameliorating the difficulty awakening in seasonal affective disorder associated with hypersomnia? J Affect Disord. 2002;69(1-3):231-236.

28. Rosenthal NE, Sack DA, Gillin JC, et al. Seasonal affective disorder. A description of the syndrome and preliminary findings with light therapy. Arch Gen Psychiatry. 1984;41(1):72-80.

29. Rosenthal NE. Diagnosis and treatment of seasonal affective disorder. JAMA. 1993;270(22):2717-2720.
30. Avery DH, Eder DN, Bolte MA, et al. Dawn simulation and bright light in the treatment of SAD: a controlled study. Biol Psychiatry. 2001;50(3):205-216.

31. Terman M, Terman JS. Circadian rhythm phase advance with dawn simulation treatment for winter depression. J Biol Rhythms. 2010;25(4):297-301.

32. Tuunainen A, Kripke DF, Endo T. Light therapy for non-seasonal depression. Cochrane Database Syst Rev. 2004;(2):CD004050.

33. Even C, Schröder CM, Friedman S, Rouillon F. Efficacy of light therapy in nonseasonal depression: a systematic review. J Affect Disord. 2008;108(1-2):11-23.

34. Gallin PF, Terman M, Remé CE, Rafferty B, Terman JS, Burde RM. Ophthalmologic examination of patients with seasonal affective disorder, before and after bright light therapy. Am J Ophthalmol. 1995;119(2):202-210.

35. Germain A, Kupfer DJ. Circadian rhythm disturbances in depression. Hum Psychopharmacol. 2008;23(7):571-585.

36. Miller AL. Epidemiology, etiology, and natural treatment of seasonal affective disorder. Altern Med Rev. 2005;10(1):5-13.

37. Pandi-Perumal SR, Trakht I, Srinivasan V, et al. Physiological effects of melatonin: role of melatonin receptors and signal transduction pathways. Prog Neurobiol. 2008;85(3):335-353.

38. Pandi-Perumal SR, Srinivasan V, Maestroni GJ, Cardinali DP, Poeggeler B, Hardeland R. Melatonin: nature's most versatile biological signal? FEBS J. 2006;273(13):2813-2838.

39. Hickie IB, Rogers NL. Novel melatonin-based therapies: potential advances in the treatment of major depression. Lancet. 2011;378(9791): 621-631.

40. Rice J, Mayor J, Tucker HA, Bielski RJ. Effect of light therapy on salivary melatonin in seasonal affective disorder. Psychiatry Res. 1995;56(3):221-228.

41. Lewy AJ, Sack RL, Miller LS, Hoban TM. Antidepressant and circadian phase-shifting effects of light. Science. 1987;235(4786):352-354.

42. Wehr TA, Duncan WC Jr, Sher L, et al. A circadian signal of change of season in patients with seasonal affective disorder. Arch Gen Psychiatry. 2001;58(12):1108-1114.

43. Danilenko KV, Putilov AA, Russkikh GS, Duffy LK, Ebbesson SO. Diurnal and seasonal variations of melatonin and serotonin in women with seasonal affective disorder. Arctic Med Res. 1994;53(3):137-145.

44. Murphy DG, Murphy DM, Abbas M, et al. Seasonal affective disorder: response to light as measured by electroencephalogram, melatonin suppression, and cerebral blood flow. Br J Psychiatry. 1993;163:327-331, 335-327.

45. Partonen T, Vakkuri O, Lönnqvist J. Suppression of melatonin secretion by bright light in seasonal affective disorder. Biol Psychiatry. 1997;42(6):509-513.

46. Lewy AJ. Circadian misalignment in mood disturbances. Curr Psychiatry Rep. 2009;11(6):459-465.

47. Pail G, Huf W, Pjrek E, et al. Bright-light therapy in the treatment of mood disorders. Neuropsychobiology. 2011;64(3):152-162.

48. Carlsson A, Svennerholm L, Winblad B. Seasonal and circadian monoamine variations in human brains examined post mortem. Acta Psychiatr Scand Suppl. 1980;280:75-85.

49. Lambert GW, Reid C, Kaye DM, Jennings GL, Esler MD. Effect of sunlight and season on serotonin turnover in the brain. Lancet. 2002;360(9348):1840-1842.

50. Neumeister A, Praschak-Rieder N, Hesselmann B, et al. Effects of tryptophan depletion in fully remitted patients with seasonal affective disorder during summer. Psychol Med. 1998;28(2):257-264.

51. Neumeister A, Turner EH, Matthews JR, et al. Effects of tryptophan depletion vs catecholamine depletion in patients with seasonal affective disorder in remission with light therapy. Arch Gen Psychiatry. 1998;55(6):524-530.

52. Lam RW, Zis AP, Grewal A, Delgado PL, Charney DS, Krystal JH. Effects of rapid tryptophan depletion in patients with seasonal affective disorder in remission after light therapy. Arch Gen Psychiatry. 1996;53(1):41-44. 
53. Neumeister A, Praschak-Rieder N, Hesselmann B, et al. Effects of tryptophan depletion in drug-free depressed patients who responded to total sleep deprivation. Arch Gen Psychiatry. 1998;55(2):167-172.

54. Lam RW, Bowering TA, Tam EM, et al. Effects of rapid tryptophan depletion in patients with seasonal affective disorder in natural summer remission. Psychol Med. 2000;30(1):79-87.

55. Neumeister A, Praschak-Rieder N, Hesselmann B, et al. Rapid tryptophan depletion in drug-free depressed patients with seasonal affective disorder. Am J Psychiatry. 1997;154(8):1153-1155.

56. Partonen T, Lönnqvist J. Seasonal affective disorder. Lancet. 1998;352(9137):1369-1374.

57. McGrath RE, Buckwald B, Resnick EV. The effect of L-tryptophan on seasonal affective disorder. J Clin Psychiatry. 1990;51(4):162-163.

58. Golden RN, Gaynes BN, Ekstrom RD, et al. The efficacy of light therapy in the treatment of mood disorders: a review and meta-analysis of the evidence. Am J Psychiatry. 2005;162(4):656-662.

59. Holsboer-Trachsler E, Hemmeter U, Hatzinger M, Seifritz E, Gerhard U, Hobi V. Sleep deprivation and bright light as potential augmenters of antidepressant drug treatment - neurobiological and psychometric assessment of course. J Psychiatr Res. 1994;28(4):381-399.

60. Martiny K, Lunde M, Undén M, Dam H, Bech P. Adjunctive bright light in non-seasonal major depression: results from clinician-rated depression scales. Acta Psychiatr Scand. 2005;112(2):117-125.

61. Beauchemin KM, Hays P. Phototherapy is a useful adjunct in the treatment of depressed in-patients. Acta Psychiatr Scand. 1997;95(5):424-427.

62. Loving RT, Kripke DF, Shuchter SR. Bright light augments antidepressant effects of medication and wake therapy. Depress Anxiety. 2002;16(1):1-3.

63. Benedetti F, Terman M. Much ado about ... a moody clock. Biol Psychiatry. 2013;74(4):236-237.

64. Buckley TM, Schatzberg AF. A pilot study of the phase angle between cortisol and melatonin in major depression - a potential biomarker? J Psychiatr Res. 2010;44(2):69-74.

65. Deltito JA, Moline M, Pollak C, Martin LY, Maremmani I. Effects of phototherapy on non-seasonal unipolar and bipolar depressive spectrum disorders. J Affect Disord. 1991;23(4):231-237.

66. Wu JC, Kelsoe JR, Schachat C, et al. Rapid and sustained antidepressant response with sleep deprivation and chronotherapy in bipolar disorder. Biol Psychiatry. 2009;66(3):298-301.
67. Benedetti F, Barbini B, Fulgosi MC, et al. Combined total sleep deprivation and light therapy in the treatment of drug-resistant bipolar depression: acute response and long-term remission rates. J Clin Psychiatry. 2005;66(12):1535-1540.

68. Klemfuss H. Rhythms and the pharmacology of lithium. Pharmacology Ther. 1992;56(1):53-78.

69. Lemoine P, Zisapel N. Prolonged-release formulation of melatonin (Circadin) for the treatment of insomnia. Expert Opin Pharmacother. 2012;13(6):895-905.

70. Kawabe K, Horiuchi F, Oka Y, Ueno S. The melatonin receptor agonist ramelteon effectively treats insomnia and behavioral symptoms in autistic disorder. Case Rep Psychiatry. 2014;2014:561071.

71. Hardeland R. Tasimelteon, a melatonin agonist for the treatment of insomnia and circadian rhythm sleep disorders. Curr Opin Investig Drugs. 2009;10(7):691-701.

72. NICE. Depression: the treatment and management of depression in adults (update). National Institute for Health and Clinical Excellence; 2009;CG23. Available from http://www.nice.org.uk/guidance/cg90/ resources/guidance-depression-in-adults-pdf. Accessed September 11, 2014.

73. Coplan JD, Gopinath S, Abdallah CG, Berry BR. A neurobiological hypothesis of treatment-resistant depression - mechanisms for selective serotonin reuptake inhibitor non-efficacy. Front Behav Neurosci. 2014;8:189.

74. Sprouse J, Braselton J, Reynolds L. Fluoxetine modulates the circadian biological clock via phase advances of suprachiasmatic nucleus neuronal firing. Biol Psychiatry. 2006;60(8):896-899.

75. Westrich L, Sprouse J, Sánchez C. The effects of combining serotonin reuptake inhibition and 5-HT7 receptor blockade on circadian rhythm regulation in rodents. Physiol Behav. 2013;110-111:42-50.

76. Kepser LJ, Homberg JR. The neurodevelopmental effects of serotonin: a behavioural perspective. Behav Brain Res. Epub May 23, 2014.

77. López-Torres J, Párraga I, Del Campo JM, Villena A; ADSCAMFYC Group. Follow up of patients who start treatment with antidepressants: treatment satisfaction, treatment compliance, efficacy and safety. $B M C$ Psychiatry. 2013;13:65.

78. Pjrek E, Winkler D, Konstantinidis A, Willeit M, Praschak-Rieder N, Kasper S. Agomelatine in the treatment of seasonal affective disorder Psychopharmacology (Berl). 2007;190(4):575-579.
ChronoPhysiology and Therapy

\section{Publish your work in this journal}

ChronoPhysiology and Therapy is an international, peer-reviewed, open access journal focusing on research into the cyclic variations and rhythmicity in physiological processes in the body and the research and development and optimal timing of administration of therapeutic targets to achieve improved outcomes and quality of life for the patient. The

\section{Dovepress}

manuscript management system is completely online and includes a very quick and fair peer-review system. Visit http://www.dovepress.com/ testimonials.php to read real quotes from published authors. 